\title{
Weary from the Future, Hong Kong
}

\section{Liz Jackson ${ }^{1}$}

Published online: 16 April 2020

(C) Springer Nature Switzerland AG 2020

\section{A Society in Turmoil}

My first time in Hong Kong (8 years ago), I felt like I was in the future. Like many visitors, I marvelled at the infrastructure, the use of technology to hasten simple transactions. Gleaming clean trains, flying through stations every $2 \mathrm{~min}$, seem a world apart from travelling through Chicago, New York, or London. Now I still feel like I live in the future, but a less hopeful one - not of glittery Futurama, but of chronic weary, with political, social, economic, and geographic dimensions.

Hong Kong has faced a public mental health crisis this last year. It emerged in relation to the anti-extradition protest movement, ${ }^{1}$ the most recent in a series of protests in Hong Kong. It started in July 2019, when the world was exposed to terrifying images of police and protestors trapped at the airport. Since then, the local economy has dramatically tumbled downward, due to decreases in tourism and travel.

Hong Kong people are known to infrequently stay in their tiny apartments. My life in Hong Kong could be roughly described as working long hours on campus during the week, hiking all weekend, and eating out every night. Yet during the protests, we started to hunker down, avoiding unnecessary social gatherings. Why risk getting teargassed? We all knew friends who had accidentally stumbled into the noxious gas, which can impact physical health, despite its abundant use by police against protestors. We began studying social media anxiously before leaving the house.

In the second half of the year, there was not an event planned - not a dinner party, or an academic lecture - without jokes or more serious discussion about a 'Plan B' in case of disruption. Our employers would also send us messages, warning us to stay home

\footnotetext{
${ }^{1}$ This movement began as a response to an extradition bill put forward by the Hong Kong government, which would allow for the transfer of fugitives outside of Hong Kong to territories where Hong Kong does not have extradition agreements, including the Mainland China and Taiwan. Protests began due to concerns that the bill could allow people from Hong Kong to be subjected to the legal system of China. Due to police reactions, and public perceptions of excessive use of tear gas, the movement picked up speed and coalesced around core concerns of pro-democracy members of the society, demanding more openness and democratic processes in society among other things (Li 2015; Kuo 2019).
}

Liz Jackson

lizjackson@hku.hk

1 University of Hong Kong, Pok Fu Lam, Hong Kong, China 
and safe during scheduled protests. Chat groups became protest information logs. We started chatting more, socializing less. Every trip through the airport had to be planned meticulously. We began travelling to the airport 4 or 5 hours early, despite travel time and security checks never taking more than half an hour, in case of complications. Most of my classes had to be made optional or end early, as trains across the region were often shut down early in the day, allegedly to repair damages, but more likely to discourage protests. Many students became uncertain of when and if they could come to classes in this case.

In one class, I showed an anxious student, who moved to Hong Kong that year from Cambodia, the website I used to know where I could travel in the area. ${ }^{2}$ It was an interactive map that anyone could add information to. I explained that the puppy dogs on the map represented where people had seen police. 'Just don't go where you see puppy dogs', I explained, gently smiling, trying to show calm.

In mid-November, my campus, my train station, and the street outside my apartment became a protest site. On a Monday morning, I was working in my office when my partner and some colleagues started warning me to get off campus, fast. Looking out my window and down the hall, I felt sceptical. It seemed quiet. I then learned that protestors had barricaded all entrances and exits to campus, trapping students and staff where they were. I tried to make my way home, before being stopped by a group of young men in black shirts (protestors): 'You cannot go this way'. As my campus is at the base of Hong Kong's Victoria Peak, I plotted a new way out, involving a kilometre's hike around the mountain, with stairs heading down to a main road off campus, from which I could walk home. I took the route with a few science professors I knew, also anxious for any exit.

The rest of that week, I watched police and protestors play cat-and-mouse from my windows and could hear what sounded like canisters of tear gas fired. I saw my apartment complex shut its massive gates, which I had never seen closed before and had previously assumed were decorative. My social life was lived fully online in chat groups with friends, who also reported what they could see from their windows and when they walked in their neighbourhoods. A few days later, I crept onto campus, to see it transformed by damages: broken glass, graffiti everywhere, barricades of broken furniture, and broken elevators and escalators, making it difficult to navigate. The road outside my apartment, a major thoroughfare, was artfully barricaded each evening, so that it was unusable each morning, preventing the 'business as usual' many in Hong Kong had been wanting for 6 long months.

I was organizing a conference at that time, as the President of the Philosophy of Education Society of Australasia (PESA), ${ }^{3}$ to be held at my university. I had been planning the conference for more than 1 year, although there were more hiccups than usual, due to catering companies closing down in Hong Kong, as well as many worried emails from would-be conference-goers, concerned about media coverage of Hong Kong. Before that point, my neighbourhood had been fairly protest-free, with only a few peaceful, inspired gatherings, and nothing worth being too worried about. On the day the protests came to the university, I was about to send out the final conference

\footnotetext{
${ }^{2}$ The map, which is now more sporadically used, is still online at https://hkmap.live/. Accessed 25 March 2020

${ }^{3}$ https://pesa.org.au/. Accessed 25 March 2020
} 
program. For the first time in its 50-year history, PESA cancelled its annual conference. At the time, no one knew whether travelling to Hong Kong would be safe. Colleagues and family members begged me to leave Hong Kong while I could.

This is just my story. Everyone in Hong Kong has theirs.

\section{Enter 2020—Cue Covid-19}

January was a month of optimism. Things that were cancelled in 2019 were put back on the calendar. I had a trip planned for early February with my partner to Singapore. It was for a work event he had. It was originally planned to be in Hong Kong in December, but was moved. This was the first of many rescheduled event casualties.

Yet there is nowhere I would rather be than Hong Kong during this current crisis. The society has functioned effectively in this case. While the universities were unclear during the protests, themselves involved in the politics of the protests, they have been decisive in 2020. Classes were moved online in February. Then, online teaching was extended through March and then April and so on.

In the context of our ongoing chaos, going online has not been too bad. I do the simplest thing: audio lectures with slides and asynchronous forums. Student presentations have been transformed into videos online. In my experience, academics in Hong Kong are not feeling very pressured by universities. There is awareness that we are in unprecedented times and that we do not need to be 'the best', but only to do 'our best', given the challenges.

But we feel sorry for our students. They have now had a full year of massive disruption, hardly a great environment for learning. As I sit in my relatively tiny apartment, working side by side with my partner for almost 3 months (in employermandated working from home and self-quarantine), I imagine them in even tinier, more crowded spaces, my rambling lectures in their ear buds, while their younger siblings are being home-schooled by their exhausted parents-turned-teachers. One group of my students are missing teaching practice in schools this term; it is their final semester, before they are to head off into schools as trained teachers. Another group of students cannot complete their dissertation research within schools. They email me regularly asking me what they should do. I wish I knew.

We are all professionally impacted. Earlier this month, I had planned to attend the Philosophy of Education Society Conference in Pittsburgh. I had two flights cancelled and changed, before I decided not to go. At that point, the USA had few cases. Yet I knew from past experience that I lived in the future. I remembered that during the Hong Kong protests, my friends and colleagues elsewhere around the world were usually fairly oblivious to what was going on in Hong Kong, only paying attention well after the fact. That few friends or family members had even asked if I was okay while Asian countries were scrambling to avoid an epidemic made me concerned that it was just a matter of time until the western world woke up to Covid-19. I also heard stories of people in the states asking for tests and not receiving them, since the virus was still being associated with travel to China, while the lack of local testing only helped maintain a sense of denial about the existence of local community transmission. So I worried about my trip. What if I caught a cold and had to see a doctor in the USA? What if travel bans changed, and I got stuck in Pittsburgh, or not let back into Hong 
Kong? Although I probably could have taken the trip and returned to Hong Kong safely, it seemed more responsible at that stage to cancel my trip. Now there is not a conference that has not been cancelled in the future.

Then, there are personal impacts. I received a message from my father and his wife a few weeks ago. They had gotten a horrific flu in northern Washington. Although there were not too many cases in that region at that time, they had all the symptoms and were never tested. Now they seem to be on the mend, but stories about reappearing cases keep me glued to my email for their updates.

My cousin, a paramedic, visited urgent care in Washington state, around the same time my dad fell ill. A young woman, she had all the symptoms, but was not tested. She was given 3 days sick leave, before being asked to work on the frontlines again. My mother is in rural Oregon. She would be hard pressed to see a doctor if she fell ill.

\section{Back to the Future}

In Hong Kong, we recovered, only to have Covid-19 strike again, with the return of many students coming from western countries this last week. With details of infected returners' local travels available, some of my friends have strengthened their selfquarantine. While most of us go out for walks and grocery shopping, a friend takes her temperature each day and has decided not to go outside for 2 weeks, as she went to the same gym as some returners who were infected.

I still seem to live in the future. Two months ago in Hong Kong, there was food hoarding, toilet paper hoarding, and grabbing up of all face masks and sanitizer. We went from spectators of the situation in Wuhan to frontliners. Now we see friends and family sharing our experience in Europe, North America, and the UK. We share with friends and colleagues about self-quarantining, social distancing, and living online. Yet it usually falls on deaf ears. It seems that few want to learn from the experiences of those abroad.

For the past few weeks, my chat groups have been full of anguish about what has been happening in the USA and the UK. Living in the future, we see that far too much of it was easily preventable. Why did not our friends and family listen to us, about social distancing and self-quarantine, about cancelling in-person classes, before things got worse? Did they think they were immune to the problems of Asia? Did they imagine they are in the developed countries, with the best healthcare in the world, while their lead politicians encourage needless loss of life, as apparently necessary for their economies? Now there are all kinds of offensive speculations, about how obedient Asians are, as if that is why Singapore, Taiwan, and Hong Kong have been pulling through. In Hong Kong, this is far from the truth. Yet those in the western world keep ignoring the experiences of those of in Asia, clinging indirectly to a kind of nationalism closed off to the rest of the world. ${ }^{4}$

Now, new jokes in the western world about self-quarantine fall on our deaf earsworse, memes, and photos of their lives lived newly at home sting, as we in Hong Kong marvel over the giant homes and apartments people suddenly feel trapped in, back

\footnotetext{
${ }^{4}$ I write about the problem with close-mindedness in the world today in Questioning Allegiance: Resituating Civic Education (Jackson 2019).
} 
west. While it is all new to my friends in the west, it feels like we have always been self-quarantining and working from home. Easter holidays are cancelled. Summer holidays are most likely cancelled.

Now the whole world is coming to the same page, wondering about life at the end of the year-and the economy and education, as we know it. As a leader of one academic society and a guide to many students and colleagues at this time, I find that my answers to questions about future conferences and activities are not as hopeful as some people would like: Wait and see. Do not spin yourself in circles needlessly. Prioritize sanity, self-care, and community care. Never mind all the things you used to do and thought you would do now.

Hong Kong is weary. I hope this is not the future for the world.

\section{References}

Jackson, L. (2019). Questioning allegiance: resituating civic education. London and New York: Routledge. Kuo, L. (2019). 'Society is suffering': Hong Kong protests spark mental health crisis. The Guardian, 22 October. https://www.theguardian.com/society/2019/oct/22/society-is-suffering-hong-kong-protestsspark-mental-health-crisis. Accessed 25 March 2020.

Li, J. (2015). Hong Kong-China extradition plans explained. BBC News, 13 December. https://www.bbc. com/news/world-asia-china-47810723. Accessed 25 March 2020. 